\title{
A seroepidemiologic study of Reston ebolavirus in swine in the Philippines
}

\author{
Yusuke Sayama ${ }^{1,2}$, Catalino Demetria ${ }^{4}$, Mariko Saito ${ }^{3}$, Rachel R Azul ${ }^{5}$, Satoshi Taniguchi ${ }^{1}$, Shuetsu Fukushi ${ }^{1}$, \\ Tomoki Yoshikawa ${ }^{1}$, Itoe lizuka ${ }^{1}$, Tetsuya Mizutani ${ }^{1}$, Ichiro Kurane ${ }^{1}$, Fidelino F Malbas $\mathrm{Jr}^{4}$, Socorro Lupisan ${ }^{4}$, \\ Davinio P Catbagan ${ }^{5}$, Samuel B Animas ${ }^{5}$, Rieldrin G Morales ${ }^{5}$, Emelinda L Lopez ${ }^{5}$, Karen Rose C Dazo ${ }^{5}$, \\ Magdalena S Cruz ${ }^{5}$, Remigio Olveda ${ }^{4}$, Masayuki Saijo ${ }^{1}$, Hitoshi Oshitani ${ }^{2,3}$ and Shigeru Morikawa ${ }^{1 *}$
}

\begin{abstract}
Background: Ebola viruses cause viral hemorrhagic fever in humans and non-human primates and are endemic in Africa. Reston ebolavirus (REBOV) has caused several epizootics in cynomolgus monkeys (Macaca fascicularis) but is not associated with any human disease. In late 2008, REBOV infections were identified in swine for the first time in the Philippines.

Methods: A total of 215 swine sera collected at two REBOV-affected farms in 2008, in Pangasinan and Bulacan, were tested for the presence of REBOV-specific antibodies using multiple serodiagnosis systems. A total of 98 swine sera collected in a non-epizootic region, Tarlac, were also tested to clarify the prevalence of REBOV infection in the general swine population in the Philippines.

Results: Some $70 \%$ of swine sera at the affected farms were positive for REBOV antibodies in the multiple serodiagnosis systems. On the other hand, none of the swine sera collected in Tarlac showed positive reactions in any of the diagnosis systems.
\end{abstract}

Conclusions: The high prevalence of REBOV infection in swine in the affected farms in 2008 suggests that swine is susceptible for REBOV infection. The multiple serological assays used in the study are thought to be useful for future surveillance of REOBV infection in swine in the Philippines.

Keyword: Reston ebolavirus, Antibody, Swine, Philippines

\section{Background}

The Ebola virus (EBOV) is an enveloped, negativestrand RNA virus belonging to the family filoviridae in the order of mononegavirale [1]. Four of the five ebolavirus species, Zaire (ZEBOV), Sudan, Tai Forest, and the recently discovered Bundibugyo ebolavirus, are endemic in continental Africa and cause a severe form of viral hemorrhagic fever with high mortality in humans and non-human primates [2-6]. Reston ebolavirus (REBOV) is sporadic in the Philippines and has caused several epizootics in cynomolgus macaques [7]. REBOV was first isolated in 1989 from cynomolgus macaques imported from the Philippines for medical research in

\footnotetext{
*Correspondence: morikawa@nih.go.jp

'Department of Virology 1, National Institute of Infectious Diseases, 4-7-1

Gakuen, Musashimurayama, Tokyo 208-0011, Japan

Full list of author information is available at the end of the article
}

the United States [7-10]. About 1,000 monkeys died or were euthanized in a quarantine facility in Reston, Virginia. Subsequently, 21 animal handlers at the Philippine exporter and four employees of the quarantine facility were found to have antibodies to the virus, indicating that they had been infected [11,12]. Epizootics in monkeys in the Philippines were then reported in 1992 and 1996, and all the epizootics have been traced back to a single monkey facility, in Calamba, Laguna in the Philippines [11,13-16]. Since the closure of the facility in 1997, no REBOV epizootics in cynomolgus monkeys have been reported.

In October 2008, REBOV infection was confirmed for the first time in swine associated with multiple epizootics of respiratory and abortion-related diseases in the Philippines [17]. In several pools of swine samples collected from geographically distant swine farms, co- 
infection with REBOV and porcine reproductive and respiratory syndrome virus (PRRSV) was confirmed [17]. Serological studies of limited scale on 13 swine sera in the affected farms failed to detect REBOV antibodies in ELISA, although PRRSV antibodies were detected [17]. It is still unclear how REBOV was spread among swine during the epizootic. Moreover, it is not clear if REBOV infection in the swine population is either sporadic and incidental or common in the Philippines. To try to answer these questions, we prepared multiple serodiagnosis systems for detecting REBOV infection in swine and analyzed swine sera obtained from the affected farms and from farms not associated with any epizootics in the Philippines. The results showed a high prevalence of REBOV infection in swine in the affected farms at the epizootics in 2008; however, REBOV antibodies were not detected in the swine population not associated with the epizootics, indicating that REBOV infection in swine in the Philippines is not common, at least in some parts of Tarlac.

\section{Results}

Detection of REBOV-NP and -GP antibodies in swine using IFA

Swine sera were analyzed for the presence of REBOVNP and -GP antibodies in IFA specific to REBOV-NP and -GP, respectively. In the IFA, none of the 49 swine sera collected in Japan showed a positive reaction (data not shown), and so they were considered to be REBOV-NP and -GP antibody negative. In the IFA specific to REBOV-NP, antibody positive swine sera showed characteristic granular staining patterns in the cytoplasm (Figure 1A), which were indistinguishable from those of REBOV-infected cynomolgus monkey sera [18] and REBOV-NP immunized rabbit sera (data not shown). Antibody-negative swine sera showed no reaction (Figure 1B). In the IFA specific to REBOV-GP, antibody positive swine sera showed characteristic cellular surface staining patterns (Figure 1C), which were indistinguishable from those of REBOV-infected cynomolgus monkey sera and REBOV-GP immunized rabbit sera (data not shown). Antibody-negative swine sera showed no reaction (Figure 1D). In Bulacan, $104(71.2 \%)$ and 115 (78.8\%) of the 146 swine sera showed positive reactions in the NP- and GP-specific IFA, respectively. In Pangasinan, each $54(78.3 \%)$ of the 69 swine sera showed positive reactions in the NP- and GP-specific IFA. In total, $158(73.5 \%)$ and $169(78.6 \%)$ of the 215 swine sera collected at the affected farms were REBOV-NP and -GP antibody positive in the IFA, respectively (Table 1). On the other hand, none of the 98 swine sera collected in Tarlac in the Philippines showed any positive reaction (Table 1).

\section{Detection of REBOV neutralizing antibodies in swine}

The VSV-pseudotype bearing REBOV-GP efficiently infected Vero E6 cells which are known to be susceptible to REBOV infection. The infectious titer of the VSVpseudotype reached $3.6 \times 10^{6} \mathrm{IU} / \mathrm{mL}$ when measured on Vero E6 cells. Infection with the VSV-pseudotype was neutralized with rabbit serum to REBOV-GP (data not shown). Swine sera were analyzed in the NT using the VSV-pseudotype. In the NT, none of the 49 swine sera collected in Japan neutralized the infection with the VSV-pseudotype on Vero E6 cells at serum dilutions of 1 in 100. These were therefore considered to be REBOV NT antibody negative. In the affected farms, 108 (74.0\%) of the 146 swine sera in Bulacan and 46 (66.7\%) of the 69 swine sera in Pangasinan showed positive reactions in the NT, respectively at a serum dilution of 1 in 100 . In total, $154(71.6 \%)$ of the 215 swine sera in the affected farms showed NT antibody positive (Table 1). NT titers of the sera were then obtained for the $34 \mathrm{NT}$ antibody positive sera in the affected farms. NT titers ranged between 100 and 12,800 with average of 790 and median of 400 (data not shown). In Tarlac, none of the 98 swine sera showed any positive reaction (Table 1 ).

\section{Detection of REBOV-NP and -GP specific antibodies in swine using IgG-ELISA}

IgG antibodies to the REBOV-NP and -GP were detected by recombinant REBOV protein-based IgGELISA. The OD values to the NP and GP of each serum sample at a dilution of 1 in 100 were plotted (Figure 2A and B), and ROC and TG-ROC curves were also drawn (Figure $2 \mathrm{C}$ to $\mathrm{F}$ ). Since the $\mathrm{OD}$ values of negative samples were very low, the cut off values defined as the values at intersection points of the sensitivity curve and specificity curve were 0.077 and 0.104 for REBOV-NP and -GP, respectively. At the cut off values, sensitivity and specificity of the assay are over 95\% in both IgG-ELISAs (Figure 2E and F). In Bulacan, $115(78.8 \%)$ and $119(81.5 \%)$ of the 146 swine sera showed positive reactions in the NP- and GP-specific IgG-ELISA, respectively. In Pangasinan, 62 (89.9\%) and $46(66.7 \%)$ of the 69 swine sera showed positive reactions in the NP- and GP-specific IgG-ELISA, respectively. In total, 177 (82.3\%) and $165(76.7 \%)$ of the 215 swine sera collected at the affected farms were REBOV-NP and -GP antibody positive in the IgGELISA, respectively (Table 1). Conversely, 1 of the 98 swine sera collected in Tarlac in the Philippines showed a positive reaction in the GP specific IgG-ELISA and 1 of the 49 swine sera collected in Japan showed a positive reaction in the $\mathrm{NP}$ - and GP-specific IgG-ELISA (Table 1). However, these results are considered to be false positives because the OD values were close to the cut off level defined by the assay, additionally all the 


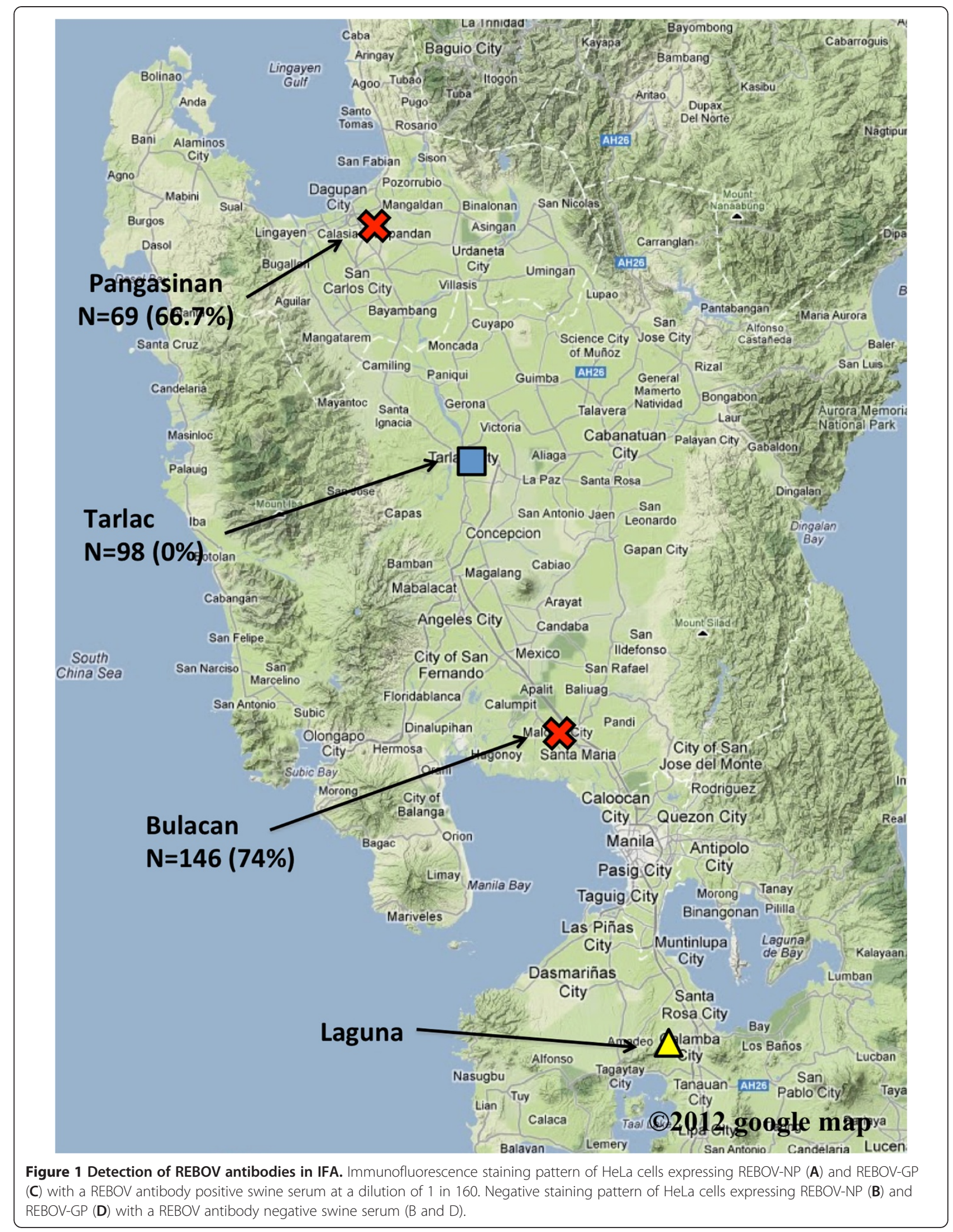


Table 1 Detection of REBOV-antibodies in swine

\begin{tabular}{|c|c|c|c|c|c|}
\hline \multirow{3}{*}{ 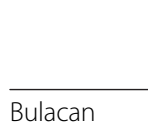 } & \multicolumn{2}{|l|}{ NP } & \multicolumn{2}{|l|}{ GP } & \multirow[t]{2}{*}{ NT } \\
\hline & IgG-ELISA & IFA & IgG-ELISA & IFA & \\
\hline & 115/146 (78.8\%) & $104 / 146(71.2 \%)$ & $119 / 146(81.5 \%)$ & $115 / 146(78.8 \%)$ & 108/146 (74.0\%) \\
\hline Pangasinan & $62 / 69$ (89.9\%) & $54 / 69$ (78.3\%) & $46 / 69(66.7 \%)$ & $54 / 69$ (78.3\%) & 46/69 (66.7\%) \\
\hline Tarlac & 0/98 (0\%) & 0/98 (0\%) & 1/98 (1.0\%) & 0/98 (0\%) & 0/98 (0\%) \\
\hline Japan & $1 / 49(2.0 \%)$ & 0/49 (0\%) & $1 / 49$ (2.0\%) & 0/49 (0\%) & $0 / 49(0 \%)$ \\
\hline
\end{tabular}

samples collected in Tarlac and Japan tested using the alternative serological assays were negative.

\section{Agreement between the serological assays detecting REBOV antibodies}

We next examined the agreement between the serological assays used in the present study. The data obtained in each assay were binarized to either positive or negative result. These binarized data were then statistically analyzed by pair-wise comparisons in nonparametric one-way ANOVA. This analysis showed that there were no significant differences between the serological assays ( $p>0.05$, data not shown). The result supports the contention that all of the five serological assays used in the present study posses similar discriminatory capacity. Thus we are confident that many REBOV antibody positive samples showed a positive reaction in all of the five assays.

\section{Discussion}

ZEBOV and Marburg virus were identified in African fruit bat species [19,20]. More recently, Marburg virus was successfully isolated from a fruit bat, Rousettus aegyptiacus [21], suggesting that fruit bats are reservoir animals of filoviruses. In the Philippines, we have recently demonstrated that an Asian fruit bat, Rousettus amplexicaudatus, has antibodies to REBOV [22]. Since the REBOV genome has not yet been detected in the bat, conclusive evidence that the bat species is a reservoir, or one of the reservoir animals, of REBOV is not available. Nevertheless, it is possible that REBOV was transmitted to swine from these bats since these bats inhabit many areas of the country, including the regions around the affected facilities both in Pangasinan and Bulacan.

In this study, we have aimed to clarify how REBOV infection was spread among swine during the REBOV
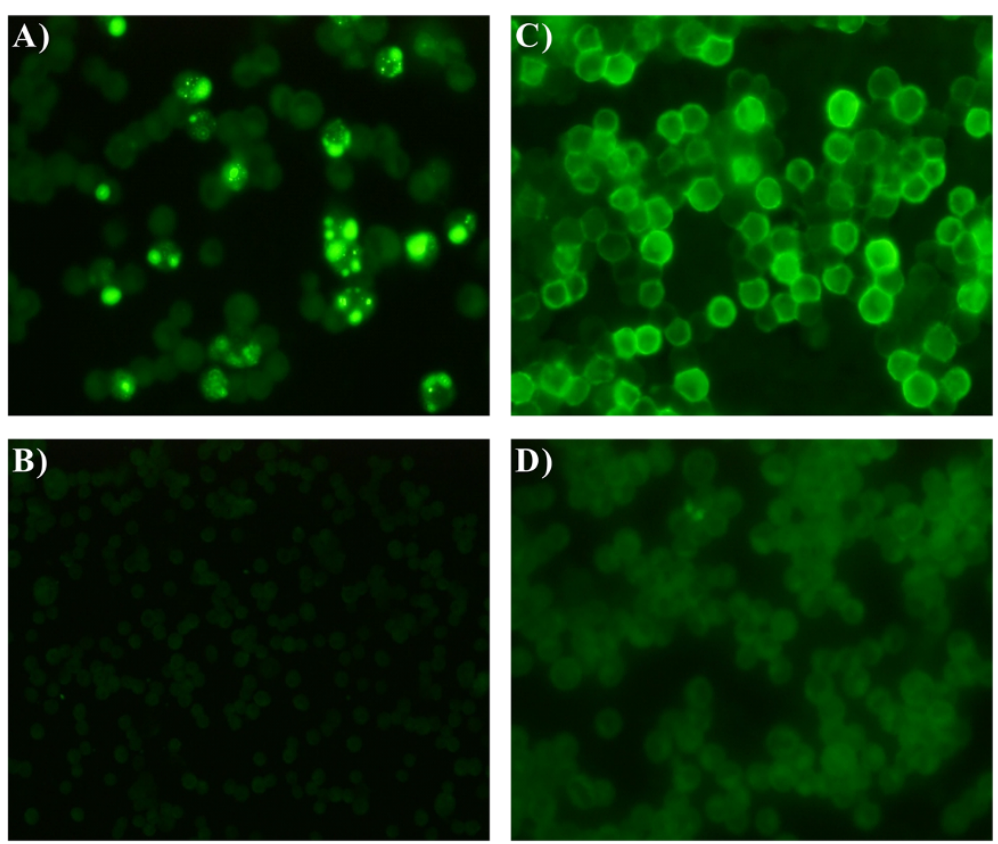

Figure 2 Distribution of OD values and ROC and TG-ROC analyses of the IgG-ELISA specific for REBOV-NP and -GP. OD values to the NP (A) and GP (B) of each serum sample at a dilution of 1 in 100 were plotted for swine group showing either IF and NT antibody positive or negative. ROC and two graph-ROC (TG-ROC) curves were analyzed and drawn using Stat Flex software. 
epizootics. We have tested 215 swine sera collected from the REBOV affected farms using IFA and IgG-ELISA specific for REBOV-NP and -GP, and NT. NT is the gold standard of serological assay in many virus infections. However, since REBOV needs to be cultured in highcontainment laboratories, we performed an alternative NT using the VSV-pseudotype bearing REBOV-GP. This avoided the use of infectious REBOV, enabling the work to be carried out at low containment. Previously it has been shown that VSV-pseudotype bearing ebolavirus GP mimicks ebolavirus infection [23], Approxymately 70\% of the swine sera from REBOV affected farms were REBOV antibody positive. This indicated that swine are susceptible to REBOV infection. Unfortunately, we could not analyze the IgM antibody responses in swine, since after the sera were heat inactivated the gamma globulin fractions were precipitated with ammonium sulfate, and reconstituted in PBS prior to be testing. An indication of the IgM responses to REBOV would have provided evidence of a recent infection. Thus, it is still unclear if REBOV infection was spread during epizootics or whether a population of the animals in the farms was infected with REBOV prior to the epizootics. The swine not associated with the epizootics, in Tarlac, are considered to be free from REBOV infection. These samples were collected in 2010, over 2 years after the epizootic, and from animals born after the epizootic. Moreover, we could not analyze the swine specimens near the affected farms in 2008. Thus, in this study, it is not clear if REBOV infection in 2008 was limited in the affected farms. Further study is necessary to conclude if the swine population in the Philippines is generally free from REBOV infection.

Recently, it has been shown that the experimental infection of swine with REBOV alone resulted in subclinical infection with rapid clearance of the virus [24]. Alternatively, ZEBOV has been shown to replicate to high titers in experimentally infected swine and to cause severe lung pathology resulting in transmission of the virus to naïve animals [25]. Thus, swine has been shown experimentally to be highly susceptible to ZEBOV infection. Furthermore, some amino acid mutations in NP and/or VP24 in ZEBOV resulted in adaptation of the virus to guinea pigs and mice $[26,27]$. Thus, we cannot rule out the possibility that mutations introduced in the REBOV genome during serial transmission in swine will result in adaptation of the virus to swine in future. In this regard, a regular serological survey of REBOV infection in swine in the Philippines is desirable. The serodiagnosis systems presented in this study might be useful for such a survey.

\section{Conclusions}

The high prevalence of REBOV infection in swine at the affected farms in 2008 suggests that swine are susceptible for REBOV infection. The multiple serological assays used in the study are thought to be useful for future surveillance of REOBV infection in swine in the Philippines.

\section{Methods}

Swine serum specimens

A total of 215 swine sera were collected from two REBOV affected pig farms, located in Pangasinan and Bulacan in 2008 (Figure 3). Of these, 146 sera were collected from swine at the farm in Bulacan, and 69 were collected from those in Pangasinan. Swine samples in the affected farms were collected under quarantine of the Philippines. The sera were kept frozen at the Research Institute for Tropical Medicine (RITM) in the Philippines until use. Ninety-eight swine sera were collected from July to September 2010 from swine aged between 2 and 20 months (median of 4.5 months) in Tarlac in the Philippines, where no swine epizootic has been documented. The swine specimens at Tarlac were collected and used under approval of IRB (No. 2009-018) of RITM, and informed consent was obtained from the farm owners. Forty-nine swine sera collected at slaughterhouse in 2006-7 in Japan, kindly supplied by Dr. T-C $\mathrm{Li}$ at the National Institute of Infectious Diseases, were used as REBOV antibody negative control sera. Swine sera were inactivated at $56^{\circ} \mathrm{C}$ for 30 minutes, and then the gamma globulin fractions were precipitated with ammonium sulfate and reconstituted in phosphate buffered saline (PBS).

\section{Immunofluorescence assay (IFA) specific to REBOV-NP and -GP using HeLa cells expressing the recombinant protein}

The entire cDNA of REBOV-GP ORF was amplified from the swine lymph node specimen used for amplification of the cDNA of NP by RT-PCR using the primers REBOV-GP/F (5'-CGA AGC TTC GAA CAT GGG GTC AGG ATA TCA ACT-3') and REBOV-GP/R (5'CGA AGC TTC AAC ACA AAA TCT TAC ATA TAC AAA G-3') (the Hind III site is underlined). The complete nucleotide sequence of the amplicon was determined to be identical to that of Reston 08A (GenBank accession number FJ621583), indicating that the specimen was collected from the same farm as that of sample group A from which Reston 08A was isolated [17]. The Hind III fragment of the amplicon was subsequently cloned into pKS336 [28], and the pKS336 plasmid with REBOV-GP, pKS336-pREBOV-GP, was used for transfection. HeLa cells were transfected with pKS336-pREBOV-GP using a FuGENE HD (Roche Diagnostics, Mannheim, Germany) according to the manufacturer's instructions. The cells transfected with the plasmids were selected with $3 \mu \mathrm{g} / \mathrm{mL}$ of blasticidin Shydrochloride (Invitrogen, CA, USA) in Dulbecco's 


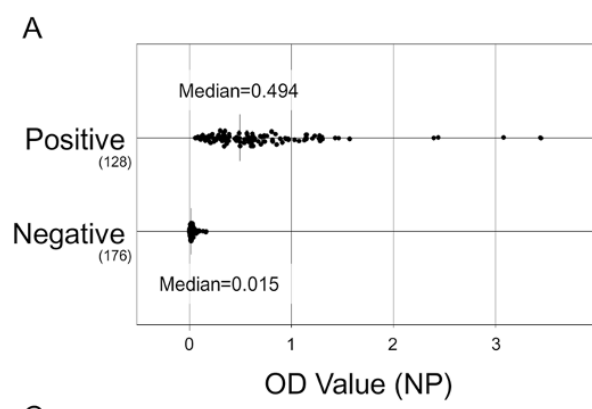

C

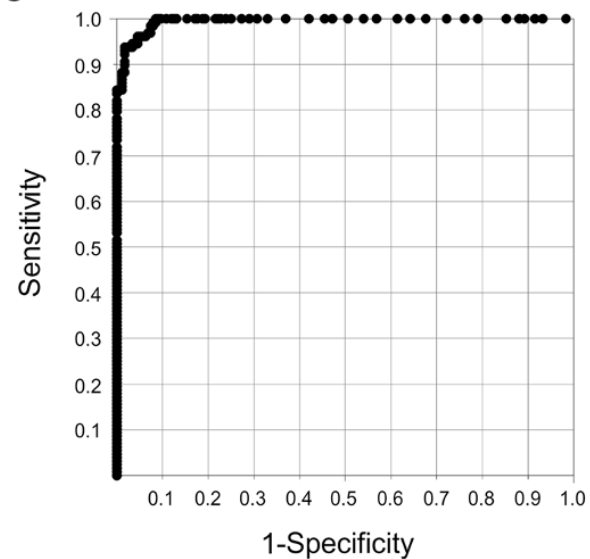

E

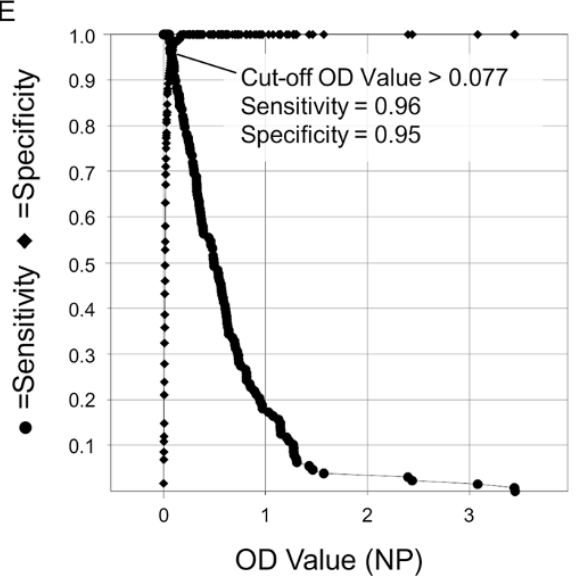

B

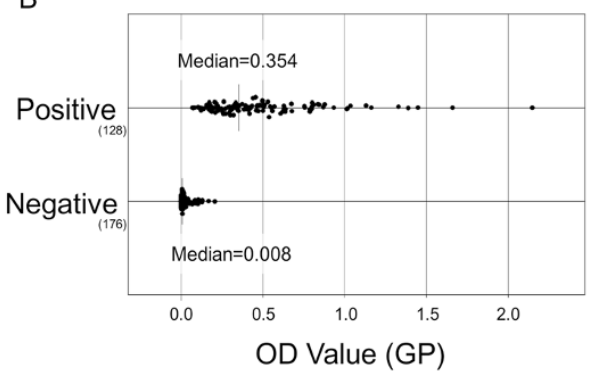

D

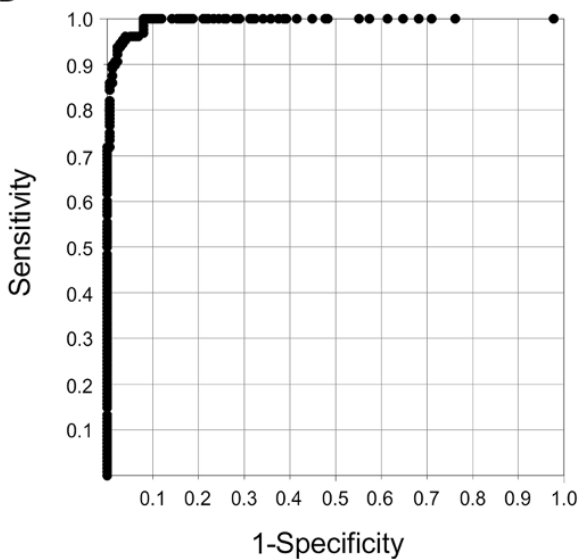

$\mathrm{F}$

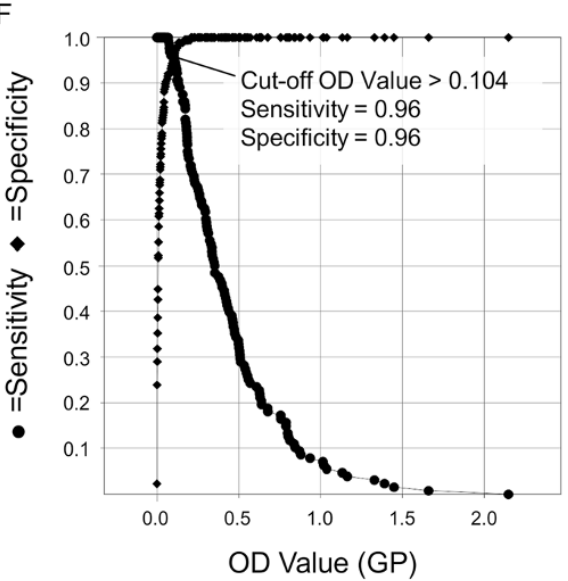

Figure 3 A topographical map showing locations in the Philippines where swine serum samples were obtained. Swine serum samples were collected at farms in three regions in the Philippines, Bulacan, Pangasinan and Tarlac. These regions were showed the numbers of specimens and percentage of positivity using NT. The three locations and Laguna, where the Ferlite monkey facility used to be located, are shown on a Google map (@2011 Google Map data @2011 AND Europa Technologies).

modified Eagle medium (DMEM) supplemented with 5\% fetal calf serum (FCS). The selected cells were analyzed for the expression of REBOV-GP in IFA using antiREBOV-GP rabbit serum. The cells expressing REBOV-GP were spotted on multiwell slide glasses, fixed in acetone, and used as antigens for IFA specific to REBOV-GP. The IFA specific to REBOV-NP was performed as described previously [18], with slight modifications. Mock-transfected HeLa cells were used as negative control antigens in the IFA. The antigen slides were incubated with serially diluted swine sera under humidified conditions at $37^{\circ} \mathrm{C}$ for 1 hour. The antigen slides were washed in PBS, then reacted with rabbit antipig IgG conjugated with fluorescein isothiocianate (FITC) (Bethyl, TX, USA) at a dilution of 1 in 100 at $37^{\circ}$ $\mathrm{C}$ for 1 hour. The slides were washed in PBS, covered with cover glasses, and examined for staining patterns under a fluorescence microscope fitted with appropriate 
barrier and excitation filters for FITC visualization. The antibody titer in the IFA was determined as the reciprocal of the highest dilution showing positive staining.

\section{Generation of vesicular stomatitis virus (VSV)-pseudotype bearing REBOV-GP}

Generation of VSV-pseudotype bearing REBOV-GP was performed as described previously [29-31]. Briefly, $293 \mathrm{~T}$ cells were transfected with pKS336-pREBOV-GP and cultured for 24 hours, and then the cells were infected with VSV $\Delta G^{*}$ (kindly supplied by Prof. M.A. Whitt, University of Tennessee) $[30,31]$ and cultured for 24 hours. The culture supernatants were then collected, filtered through a $0.22 \mu \mathrm{m}$-pore-size filter, and stored at $-80^{\circ} \mathrm{C}$ until use. The infectious titer (infectious unit, IU) of VSV-pseudotype on Vero E6 cells was determined by counting the number of Green Fluorescent Protein (GFP)-expressing cells.

\section{Neutralization test (NT)}

The sera were diluted twofold from 1 in 100 with DMEM containing 5\% FCS and 1,000 IU of VSVpseudotype bearing REBOV-GP. The mixture was incubated for 1 hour at $37^{\circ} \mathrm{C}$, then inoculated onto Vero E6 cells seeded on 96-well plates. The numbers of VSVpseudotype infected cells were determined by counting of the number of GFP-positive cells according to the methods described previously $[23,29,30]$. NT titers of the tested sera were defined as the reciprocals of the highest dilutions at which more than $50 \%$ inhibition of infectivity was observed. Serum samples were considered to be NT antibody negative when less than $50 \%$ inhibition of infectivity was observed at a dilution of 1 in 100 .

\section{Recombinant baculoviruses expressing recombinant REBOV proteins}

cDNA of REBOV nucleoprotein (NP) open reading frame (ORF) from a swine lymph node specimen collected at the farm in Bulacan was amplified by reverse transcription polymerase chain reaction (RT-PCR), and the nucleotide sequence of the amplicon was determined to be identical to that of Reston 08A. The cDNA was subcloned into pGEMTeasy (Promega, WI, USA) and used for the following PCR template. PCR was performed using the plasmid clone to add BamHI linker with primers REBOV-NP/F (5'-GGG CTA GCG GAT CCA AGT CGA TAT GGA TCG TGG GAC C-3') and REBOV-NP/R (5'-TTG CGG CCG CGG ATC CCT GAT GGT GCT GCA AGA TTG-3') (the restriction site is underlined). A BamHI-digested fragment of the plasmid was then subcloned into pAcYM1-C-His plasmid, a derivative of pAcYM1 plasmid [32] carrying eight histidine coding sequences just downstream of the BamHI site, to construct pAcYM1-His-pREBOV-NP. A recombinant baculovirus, Ac-His-pREBOV-NP, was generated using a previously described method [33]. The recombinant baculovirus, which expresses the ectodomain of REBOVglycoprotein (GP) with a histidine-tag at its carboxyl terminus [22], was used to prepare recombinant REBOV$\mathrm{GP}$ for IgG-ELISA. A baculovirus (Ac- $\Delta \mathrm{P}$ ) that lacks the polyhedorin gene was used to prepare a negative-control antigen in insect cells.

\section{Expression and purification of recombinant NP and GP of REBOV in baculovirus}

Tn5 insect cells were infected with Ac-His-pREBOV-NP and Ac-His-REBOV-GP and then incubated at $26^{\circ} \mathrm{C}$ for 72 hours and 48 hours, respectively. The cells were washed in PBS, lyzed in PBS containing 1\% NP40 and $8 \mathrm{M}$ urea, and then clarified by centrifugation at $8,000 \mathrm{rpm}$ for $10 \mathrm{~min}$. The supernatant fraction was collected, and recombinant REBOV-NP and REBOV-GP were purified using a $\mathrm{Ni} 2$ +-resin purification system (QIAGEN, Düsseldorf, Germany) according to the manufacturer's instructions. The expression and purification of REBOV-NP and REBOV-GP were confirmed in 10\% sodium dodecyl sulfate polyacrylamide gel electrophoresis (SDS-PAGE) and Coomassie Brilliant Blue R-250 staining Tn5 cells infected with Ac- $\Delta \mathrm{P}$ were processed similarly and used as negative control antigen in the ELISAs. The purified antigens and negative control antigen were kept at $-80^{\circ} \mathrm{C}$ until use.

\section{IgG-ELISA}

Swine sera were analyzed for the presence of antibodies to REBOV-NP and REBOV-GP in IgG-ELISA, essentially as described previously [22,34,35]. Briefly, half of the wells of the ELISA plates (Falcon, NJ, USA) were coated with a predetermined optimal quantity (approximately $100 \mathrm{ng} /$ well) of each purified recombinant protein, and the rest of the wells were coated with the negative control antigens. After washing the plates three times in PBS containing $0.05 \%$ Tween-20 (T-PBS; SIGMAALDRICH, MO, USA), each well was incubated with $200 \mu \mathrm{L}$ of T-PBS containing 5\% skim milk (MT-PBS; Yukijirushi, Hokkaido, Japan) for 1 hour at $37^{\circ} \mathrm{C}$. After washing the plates three times in T-PBS, the antigencoated and negative-control-antigen-coated wells were inoculated with the test samples $(100 \mu \mathrm{L} /$ well $)$ in MTPBS at a dilution of 1 in 100, incubated for 1 hour at $37^{\circ}$ $\mathrm{C}$, and washed in T-PBS. Then, each well was incubated with a Protein A/G conjugated with horseradish peroxidase at a dilution of 1 in 1,500 (PIERCE, IL, USA) in MT-PBS for 1 hour at $37^{\circ} \mathrm{C}$. The plates were washed three times, and $100 \mu \mathrm{L}$ of ABTS solution (Roche Diagnostics, Mannheim, Germany) was added to each well. The plates were incubated for $30 \mathrm{~min}$, and the optical density (OD) was measured at $405 \mathrm{~nm}$ with a reference at $490 \mathrm{~nm}$. The adjusted ODs for each tested sample 
were calculated by subtracting the ODs of the negativecontrol-antigen-coated wells from those of the corresponding REBOV-antigen-coated wells.

\section{Statistical methods}

Sensitivity, specificity and predictive values for positive and negative tests were calculated by standard methods. Sensitivity and specificity were defined as the probability that the target assay result was positive when the IFAs specific to REBOV-NP and -GP and NT showed positive and the probability that the target assay result was negative when the IFAs and NT showed negative, respectively. Receiver operating characteristics (ROC) and two graph-ROC (TG-ROC) curves were analyzed using Stat Flex software (Artech Co. Ltd., Osaka, Japan) [36,37]. To examine the agreement between the serological assays used in the present study, we employed Friedman test with Dunn's post-hoc test $[38,39]$ using GraphPad Prism using pair-wise comparisons in nonparametric one-way ANOVA.

\section{Competing interests}

The authors declare that they have no competing interests.

\section{Authors' contributions}

YS participated in the study design, the experimental work, the analysis interpretation of the data and drafted the manuscript. CD, MS (Tohoku University), RA, ST, SF, II, TM, IK, FFMJ, SL, DPC, SBA, RGM, ELL, KRCD, MSC, $\mathrm{RO}, \mathrm{MS}$ and $\mathrm{HO}$ participated in the study design, the experimental work, and helped draft the manuscript. TY participated in the statistical analysis of the data. SM conceived and designed the study and participated in the analysis and interpretation of the data and writing of the manuscript. All authors read and approved the final manuscript.

\section{Authors' information}

YS is a graduate student at Department of Virology, Tohoku University Graduate School of Medicine. CD, FFMJ, SL, and RO are staff at Research Institute for Tropical Diseases. MS and HO are staff at Department of Virology, Tohoku University Graduate School of Medicine. RA, DPC, SBA, RGM, ELL, KRCD, and MSC are staff at Bureau of Animal Industry. ST, SF, TY, II, TM, IK, MS and SM are staff at National Institute of Infectious Disease.

\section{Acknowledgements}

We gratefully acknowledge Ms Momoko Ogata at the National Institute of Infectious Diseases, Japan, and the staff of the Research Institute for Tropical Medicine and the Bureau of Animal Industry, the Philippines, for their technical assistance. We also acknowledge Dr. Tian Cheng Li at the National Institute of Infectious Diseases, Japan, for supplying the swine sera collected in Japan. We sincerely acknowledge Dr. Roger Hewson at the Centre for Emergency Preparedness and Response, Health Protection Agency, UK, for critical reading the manuscript.

This work was supported in part by a grant-in-aid to S.M. from the Ministry of Health, Labor and Welfare of Japan (grants H22-shinkou-ippan-006) and to H.O. for The Japan Initiative for Global Research Network on Infectious Diseases (J-GRID) from the Ministry of Education, Culture, Sports, Science, and Technology of Japan.

\section{Author details}

'Department of Virology 1, National Institute of Infectious Diseases, 4-7-1 Gakuen, Musashimurayama, Tokyo 208-0011, Japan. ${ }^{2}$ Department of Virology, Tohoku University Graduate School of Medicine, 2-1 Seiryo-machi, Aoba-ku, Sendai, Miyagi 980-8575, Japan. ${ }^{3}$ Tohoku-RITM Collaborating Research Center for Emerging and Reemerging Infectious Diseases, FILINVEST Corporate City, Alabang, Muntinlupa City 1781, Philippines. ${ }^{4}$ Research Institute for Tropical Medicine, FILINVEST Corporate City, Alabang, Muntinlupa City 1781,
Philippines. ${ }^{5}$ Bureau of Animal Industry, Elliptical Road, Diliman, Quezon City 1107, Philippines.

Received: 23 February 2012 Accepted: 12 June 2012

Published: 18 June 2012

\section{Reference}

1. Feldmann H, Klenk HD, Sanchez A: Molecular biology and evolution of filoviruses. Arch Virol Suppl 1993, 7:81-100.

2. Ebola haemorrhagic fever in Zaire, 1976: Bull World Health Organ 1978, 56(2):271-293.

3. Khan AS, Tshioko FK, Heymann DL, Le Guenno B, Nabeth P, Kerstiens B, Fleerackers Y, Kilmarx PH, Rodier GR, Nkuku O, et al: The reemergence of Ebola hemorrhagic fever, Democratic Republic of the Congo, 1995. Commission de Lutte contre les Epidemies a Kikwit. J Infect Dis 1999, 179(Suppl 1):S76-86.

4. Sadek RF, Khan AS, Stevens G, Peters CJ, Ksiazek TG: Ebola hemorrhagic fever, Democratic Republic of the Congo, 1995: determinants of survival. J Infect Dis 1999, 179(Suppl 1):S24-27.

5. Outbreak of Ebola haemorrhagic fever: Uganda, August 2000-January 2001. Wkly Epidemiol Rec 2001, 76(6):41-46.

6. Towner JS, Sealy TK, Khristova ML, Albarino CG, Conlan S, Reeder SA, Quan PL, Lipkin WI, Downing R, Tappero JW, et al: Newly discovered ebola virus associated with hemorrhagic fever outbreak in Uganda. PLOS Pathog 2008, 4(11):e1000212.

7. Miranda ME, White ME, Dayrit MM, Hayes CG, Ksiazek TG, Burans JP: Seroepidemiological study of filovirus related to Ebola in the Philippines. Lancet 1991, 337(8738):425-426.

8. Geisbert TW, Rhoderick JB, Jahrling PB: Rapid identification of Ebola virus and related filoviruses in fluid specimens using indirect immunoelectron microscopy. J Clin Pathol 1991, 44(6):521-522.

9. Geisbert TW, Jahrling PB: Use of immunoelectron microscopy to show Ebola virus during the 1989 United States epizootic. J Clin Pathol 1990, 43(10):813-816.

10. Geisbert TW, Jahrling PB, Hanes MA, Zack PM: Association of Ebola-related Reston virus particles and antigen with tissue lesions of monkeys imported to the United States. J Comp Pathol 1992, 106(2):137-152.

11. Hayes CG, Burans JP, Ksiazek TG, Del Rosario RA, Miranda ME, Manaloto CR, Barrientos AB, Robles CG, Dayrit MM, Peters CJ: Outbreak of fatal illness among captive macaques in the Philippines caused by an Ebola-related filovirus. Am J Trop Med Hyg 1992, 46(6):664-671.

12. Update: evidence of filovirus infection in an animal caretaker in a research/service facility. MMWR Morb Mortal Wkly Rep 1990, 39(17):296-297.

13. Ikegami T, Miranda ME, Calaor AB, Manalo DL, Miranda NJ, Niikura M, Saijo M, Une Y, Nomura Y, Kurane I, et al: Histopathology of natural Ebola virus subtype Reston infection in cynomolgus macaques during the Philippine outbreak in 1996. Exp Anim 2002, 51(5):447-455.

14. Rollin PE, Williams RJ, Bressler DS, Pearson S, Cottingham M, Pucak G, Sanchez A, Trappier SG, Peters RL, Greer PW, et al: Ebola (subtype Reston) virus among quarantined nonhuman primates recently imported from the Philippines to the United States. I Infect Dis 1999, 179(Suppl 1):S108-114.

15. Jahrling PB, Geisbert TW, Jaax NK, Hanes MA, Ksiazek TG, Peters CJ: Experimental infection of cynomolgus macaques with Ebola-Reston filoviruses from the 1989-1990 U.S. epizootic. Arch Virol Supp/ 1996, 11:115-134.

16. Miranda ME, Miranda NL: Reston ebolavirus in humans and animals in the Philippines: a review. J Infect Dis 2011, 204(Suppl 3):S757-760.

17. Barrette RW, Metwally SA, Rowland JM, Xu L, Zaki SR, Nichol ST, Rollin PE, Towner JS, Shieh WJ, Batten B, et al: Discovery of swine as a host for the Reston ebolavirus. Science 2009, 325(5937):204-206.

18. Ikegami T, Saijo M, Niikura M, Miranda ME, Calaor AB, Hernandez M, Manalo DL, Kurane I, Yoshikawa Y, Morikawa S: Development of an immunofluorescence method for the detection of antibodies to Ebola virus subtype Reston by the use of recombinant nucleoproteinexpressing HeLa cells. Microbiol Immunol 2002, 46(9):633-638.

19. Leroy EM, Kumulungui B, Pourrut X, Rouquet P, Hassanin A, Yaba P, Delicat A, Paweska JT, Gonzalez JP, Swanepoel R: Fruit bats as reservoirs of Ebola virus. Nature 2005, 438(7068):575-576. 
20. Towner JS, Pourrut X, Albarino CG, Nkogue CN, Bird BH, Grard G, Ksiazek TG, Gonzalez JP, Nichol ST, Leroy EM: Marburg virus infection detected in a common African bat. PLoS One 2007, 2(1):e764.

21. Towner JS, Amman BR, Sealy TK, Carroll SA, Comer JA, Kemp A, Swanepoel R, Paddock CD, Balinandi S, Khristova ML, et al: Isolation of genetically diverse Marburg viruses from Egyptian fruit bats. PLoS Pathog 2009, 5(7):e1000536.

22. Taniguchi S, Watanabe S, Masangkay JS, Omatsu T, Ikegami T, Alviola P, Ueda N, Iha K, Fujii H, Ishii Y, et al: Reston Ebolavirus antibodies in bats, the Philippines. Emerg Infect Dis 2011, 17(8):1559-1560.

23. Ito H, Watanabe S, Takada A, Kawaoka Y: Ebola virus glycoprotein: proteolytic processing, acylation, cell tropism, and detection of neutralizing antibodies. J Virol 2001, 75(3):1576-1580.

24. Marsh GA, Haining J, Robinson R, Foord A, Yamada M, Barr JA, Payne J, White J, Yu M, Bingham J, et al: Ebola Reston virus infection of pigs: clinical significance and transmission potential. J Infect Dis 2011, 204(Suppl 3):S804-809.

25. Kobinger GP, Leung A, Neufeld J, Richardson JS, Falzarano D, Smith G, Tierney K, Patel A, Weingartl HM: Replication, Pathogenicity, Shedding, and Transmission of Zaire ebolavirus in Pigs. J Infect Dis 2011, 204(2):200-208.

26. Volchkov VE, Chepurnov AA, Volchkova VA, Ternovoj VA, Klenk HD: Molecular characterization of guinea pig-adapted variants of Ebola virus. Virology 2000, 277(1):147-155

27. Ebihara H, Takada A, Kobasa D, Jones S, Neumann G, Theriault S, Bray M, Feldmann $\mathrm{H}$, Kawaoka Y: Molecular determinants of Ebola virus virulence in mice. PLoS Pathog 2006, 2(7):e73.

28. Saijo M, Qing T, Niikura M, Maeda A, Ikegami T, Sakai K, Prehaud C, Kurane I, Morikawa S: Immunofluorescence technique using HeLa cells expressing recombinant nucleoprotein for detection of immunoglobulin $\mathrm{G}$ antibodies to Crimean-Congo hemorrhagic fever virus. J Clin Microbiol 2002, 40(2):372-375.

29. Fukushi S, Mizutani T, Saijo M, Kurane I, Taguchi F, Tashiro M, Morikawa S: Evaluation of a novel vesicular stomatitis virus pseudotype-based assay for detection of neutralizing antibody responses to SARS-CoV. J Med Virol 2006, 78(12):1509-1512.

30. Fukushi S, Mizutani T, Saijo M, Matsuyama S, Taguchi F, Kurane I, Morikawa S: Pseudotyped vesicular stomatitis virus for functional analysis of SARS coronavirus spike protein. Adv Exp Med Biol 2006, 581:293-296.

31. Takada A, Robison C, Goto H, Sanchez A, Murti KG, Whitt MA, Kawaoka Y A system for functional analysis of Ebola virus glycoprotein. Proc Natl Acad Sci USA 1997, 94(26):14764-14769.

32. Matsuura Y, Possee RD, Overton HA, Bishop DH: Baculovirus expression vectors: the requirements for high level expression of proteins, including glycoproteins. J Gen Virol 1987, 68(Pt 5):1233-1250.

33. Kitts PA, Ayres MD, Possee RD: Linearization of baculovirus DNA enhances the recovery of recombinant virus expression vectors. Nucleic Acids Res 1990, 18(19):5667-5672.

34. Saijo M, Niikura M, Ikegami T, Kurane I, Kurata T, Morikawa S: Laboratory diagnostic systems for Ebola and Marburg hemorrhagic fevers developed with recombinant proteins. Clin Vaccine Immunol 2006, 13(4):444-451.

35. Ikegami T, Saijo M, Niikura M, Miranda ME, Calaor AB, Hernandez M, Manalo DL, Kurane I, Yoshikawa Y, Morikawa S: Immunoglobulin G enzyme-linked immunosorbent assay using truncated nucleoproteins of Reston Ebola virus. Epidemiol Infect 2003, 130(3):533-539.

36. Greiner M, Sohr D, Gobel P: A modified ROC analysis for the selection of cut-off values and the definition of intermediate results of serodiagnostic tests. J Immunol Methods 1995, 185(1):123-132.

37. Zweig MH, Campbell G: Receiver-operating characteristic (ROC) plots: a fundamental evaluation tool in clinical medicine. Clin Chem 1993. 39(4):561-577.

38. Demsar J: Statistical Comparisons of Classifiers over Multiple Data Sets. Journal of Machine Learning Research 2006, 7:1-30.

39. Dunn OJ: Multiple Comparisons Among Means. J Am Stat Assoc 1961, 56(293):52-64

\section{Submit your next manuscript to BioMed Central and take full advantage of:}

- Convenient online submission

- Thorough peer review

- No space constraints or color figure charges

- Immediate publication on acceptance

- Inclusion in PubMed, CAS, Scopus and Google Scholar

- Research which is freely available for redistribution 